\title{
Property tax administration in developing countries: alternatives for land registration and cadastral mapping
}

\author{
ROBERT B. KENT \\ University of Akron
}

\begin{abstract}
SUMMARY
The property tax is a widely used fiscal tool in many developing countries. However, property tax evasion and underpayment are common. This fact underscores the need for governments to administer the property tax effectively if they are to maximize revenue for development. A workable system of land registration and cadastral mapping is one of the principal prerequisites for efficient administration of the property tax. This paper examines alternative methods of land registration and cadastral mapping appropriate for governments in developing countries. The registration of deeds and titles is discussed, as are the most appropriate means for their implementation. Similarly, the different types of cadastral systems, fiscal, legal and multi-purpose, and the survey methods necessary for their implementation, are reviewed.
\end{abstract}

\section{INTRODUCTION}

The property tax is one of the most common tax levies in developed and developing countries. Its popularity as a revenue source is based on the fact that real property, because of its permanence and immobility, is readily identified, catalogued and taxed. Unfortunately, in many developing countries receipts from the property tax are low, because of high rates of tax evasion and underpayment of tax obligations. These problems with the collection of the property tax emphasize the need for its improved administration if it is to benefit governments and communities in developing countries to the fullest.

The requirements for the successful administration of the property tax have been stated in one form or another by several authors. Fitch $(1965$, p. 465) identifies four requirements: acceptance by a large majority of the taxpayers; a body of workable tax concepts easily understood by government tax officials and taxpayers; a corps of personnel capable of fairly and equitably enforcing the collection of property taxes; and adequate administrative tools including machines, records and maps. Discussing the possibilities for a viable land system in Bolivia, Sazama (1970, pp. 316-317) invokes three requisites: a strong base of popular and political support which supports the implementation of the tax; administrative capacity sufficient to efficiently and fairly maintain the tax rolls; and a good cadastral survey incorporating a property registry and property assessments. In a later paper, Sazama and Davis (1973, p. 652) emphasize the need to overcome political barriers, effectively thwart evasion, appropriately adjust assessments for inflation,

Dr. Kent is in the Department of Geography, University of Akron, Akron, Ohio 44325, USA.

0271-2075/88/010099-15\$07.50

(C) 1988 by John Wiley \& Sons, Ltd. 
and provide for a cadastral survey or, at the minimum, clear land titling. Bird (1974, p. 100) makes one of the strongest statements, stating that land taxes stand or fall on the basis of the land survey information available.

The remainder of this paper examines different approaches to land registration and cadastral mapping which can be employed to assist in the improvement of the administration of the property tax in developing countries.

\section{LAND REGISTRATION}

In order to tax real property, the property and its owner, or user, must be known to the government agency responsible for the collection of the tax. The registration of land parcels, and the identification of their owners, is a practice of considerable antiquity. The Egyptians are reported to have maintained such records in the Royal Registry as early as $3000 \mathrm{BC}$ and the Domesday Book, created in England after the Norman Conquest around $1000 \mathrm{AD}$, served among other things as a land register providing the name of the proprietor, tenure conditions, land area and details for the assessment of land (Larsson, 1971, p. 33).

Land registration for fiscal purposes also has a long history in Asia. Some form of land registration was practised in Sri Lanka for several centuries prior to European colonization, although its utility was severely impaired by the absence of any kind of systematic revision (Codrington, 1938, p. 60). Land registration in Nepal was well established by the mid-1700s and based on a system which, according to one observer, compared very favourably with those in effect in areas of India under British rule (Regmi, 1963, p. 153). In China land was registered for tax purposes during the Ch'ing dynasty (1644-1911). However, the amount of land taxes collected varied considerably from period to period as a function of the efficiency with which the register was maintained (Wang, 1971, p. 839). Likewise, land was registered for tax purposes by the end of the sixteenth century in Japan, but contrary to the experiences in Sri Lanka and China the registration process was based on a comprehensive survey, which identified, measured and classified land for tax purposes (Bird, 1977, p. 164). Bird (1977, p. 164) suggests that this early effort at land registration based on a cadaster was instrumental in the successful administration of the land tax nearly three centuries later, during the Meiji period (1868-1911).

Despite this long historical and cross-cultural experience with land registration for tax purposes, the subject still commands considerable interest. This is due to the variety of approaches which may be taken, and to myriad problems involved in the accurate establishment of a land register and the tremendous effort required to maintain it. The following pages review the various approaches to land registration and the problems associated with them.

Modern land registration can be defined as falling into two broad categories: the registration of deed and the registration of title. Both share the goal of providing open and public dealings in land, but they vary considerably in the complexity of their administration and impact on the collection of property taxes. Basically the two systems of registering land are distinguished in the significance and implications of the registration document. 


\section{Deed registration}

Deed registration in its simplest form provides evidence that a property transaction has occurred, and from whom and to whom the property has been transferred. The registration of the deed does not guarantee that either party had a legal right to enter into the transaction; nor does it guarantee that the transaction is valid. Under this method of deed registration, the documents evidencing the property transfer are simply presented to the registrar who, accepting them on their face value, abstracts and enters the documents' contents in the property register. The principal drawbacks of this method of deed registration are that the validity of the documents is not examined, and that a separate file is not maintained for each land parcel (Maini, 1967, p. 131).

The registration of deed may, however, be accomplished in a slightly more rigorous manner, and in some countries more advanced forms of deed registration are employed. Frequently these operate, as in Kenya (Maini, 1967, p. 132), so that the registrar will not enter a deed on the register unless he has examined it and feels it legally valid. Further, for each property parcel a separate file is maintained, where copies of all deeds and other documents relevant to the ownership of the property parcel are kept. Basically, whatever system of deed registration is employed, the registration document serves legally to document the transfer of land from one party to the other. Its basic function is to protect the property owner with the registered deed from claims based on unregistered documents. Deed registration does not certify that the land or property was actually owned by the seller, or that it is free of liens or mortgages, and hence provides no security of title. Finally, it is significant to note that proof of the ownership of property is provided by the deed, and not by its recording in the register.

\section{Title registration}

Title registration, on the other hand, is a more complex process, but one which provides greater protection to the registered property owner. The principal feature of title registration which distinguishes it from the registration of deeds is that it certifies that the seller has clear title, or indicates the nature of liens on the property. Normally, it also guarantees that in case of fraud or error in the land transaction, the state will provide compensation to the injured party. Finally, proof of property ownership is based on the register, and not the documents like deeds or property transfer certificates (Elias, 1971, p. 353).

A variety of prerequisites for the implementation of a system of title registration have been suggested. Larsson (1971) proposes that a titles register must be kept according to clearly defined land units, be constantly maintained and up to date, be the proof of title, and be maintained by the central government. Maini (1967, p. 136) believes that the registration of title should provide security, be completely accurate in land and ownership descriptions, be inexpensive enough so all landowners can afford to register their titles, be simple enough to be understood by all landowners, be accessible through local registration offices, and provide compensation for loss. Registers should also be accessible and available for public inspection (Bentsi-Enchill, 1964, p. 310).

The benefits which are said to accrue, as a result of title registration, include 
increased security of title, the availability of credit through the use of a property title as security, increased facility in property transfers, improved public administration of land, and as an aid in the introduction or improvement of systems of taxation based on land (West, 1969, pp. 212-214).

\section{Implementation}

There are three ways to implement land registration: voluntary, compulsorysporadic, and compulsory-systematic (Larsson, 1971, pp. 37-38). The most attractive feature of voluntary registration is that it is easy to initiate. Using this approach land parcels are only registered at the request of the property owner. Needless to say, it has the disadvantage of requiring a great deal of time before any significant quantity of land is included in the land registration system. A further disadvantage of the method is that the per-unit costs of the registration programme can be very high. This results from the need for individual surveys of each property at the time it is registered, and the necessity of a visit by a registry official to investigate the property title or deed.

Compulsory-sporadic land registration is different. Instead of land being registered at the discretion of the property owner, under this type of registration the law specifies that whenever there are dealings in land (e.g. sales, transfers, grants, partitions, consolidations) the affected parcels must be registered at the time of the transaction. While this method tends to bring property parcels into the system more rapidly than the voluntary approach, it too suffers from very high perunit costs. On the other hand, compulsory-systematic land registration is considerably less costly in per-unit terms because all properties in a given area are registered (and in some cases surveyed and adjudicated) at the same time. Nevertheless, the start-up costs of this procedure are greater than either of the previous two, and this tends to make it less attractive.

The prohibitive start-up costs may be reduced if a phased approach is adopted. The most realistic approach to title registration is to adopt a methodology utilizing both compulsory-sporadic and systematic registration. Using such a scheme, compulsory-systematic registration would be undertaken in areas where potential tax revenues would be the greatest. At the same time, land parcels in other areas would be required to be registered whenever transactions involving them occurred. Employing a combination of these two procedures, eventually it would be possible to bring most land on to the land registry at an acceptable cost.

Implementation of land registration can provide a vital contribution to the process of property taxation. First and foremost, a system of land registration, whether it be of deeds or titles, identifies the property owner and the property parcel. The identity of the owner is of obvious importance when preparing tax rolls and levying the property tax when the tax is collected in personam. If the tax is collected in rem, the identity of the owner is not of such concern, but rather the identity of the individual who accepts responsibility for paying the tax on the land. Aside from the identity of the property owner and property characteristics, property sales information can be included with other registration data. This information may be utilized to tax property transfers, and for providing a basis for establishing assessments for the real property tax, based on capital value. While it is unreasonable to expect properties to change hands frequently enough for sales data 
to be the only basis upon which the assessments are determined, the information collected from a relatively few transactions can be used by assessors, at least in part, to form a basis for capital valuations on all properties.

Property tax systems based on the concept of site value can also utilize property sales data for determining site value. Using the capital value of a property as a base (computed from sales data), the value of improvements on a piece of property and the cost of their demolition may be subtracted giving a crude measure of site value (Hicks, 1970, pp. 18-19). However, as Hicks points out, this simplified approach to determining site value can lead to serious inequity in tax assessments. For example, two property parcels, exactly the same in terms of site value characteristics, can end up being taxed at very different rates as a result of the different type and condition of the improvements on each property. Site value taxation based on more complex, but realistic, site criteria avoid this inequitable result.

Land registration systems which require the reporting of sales prices at the time of property transfers and sales can be especially useful when property taxation is based on self-assessments. Considering the difficulties and poor record of valuations and property taxation based on self-assessment, sales data from land registration systems can make a positive contribution towards monitoring the accuracy of self-assessments.

The difficulties inherent in a property tax system utilizing self-assessment focus primarily on non-compliance and under-assessment. Experiences in Colombia and Panama illustrate the frequent results of using such a technique. Self-assessment for property taxation was attempted in rural areas of Colombia in 1954 and in 1963 and failed both times, despite government efforts to keep assessments at or near market value by stating that if the owner's land was expropriated the owner would only be eligible to receive as much compensation as the declared value (Davis, 1970, pp. 147-148). Self-assessment has been used in urban and rural areas of Panama with limited success. In Panama City, after years of unsuccessful administration, selfassessment ended in the late 1950s with the establishment of a cadastral commission charged with mapping and evaluating all properties. In the rural areas, however, self-assessment continued (Taylor et al., 1964, pp. 64-67). Under the Panamanian system the property owner could not declare a value for his property lower than any value previously declared for it either by himself or by a previous owner. In an attempt to keep property values realistic, the National Bank of Panama, which makes loans on real estate, limited their loans to 60 per cent of the property valuation declared by the owner.

The whole question of self-assessments has been examined in considerable detail by Strasma, who has suggested that such an approach, flawed though it is, may indeed be the only realistic alternative for developing countries (Strasma, 1965, p. 7). Self-assessment is used in Peru with modest success, although some municipalities (Huancayo, Cajamarca and Miraflores) have established cadastral mapping systems which permit checking of an owner's declaration, and hence ensure more accurate self-assessments. Nevertheless, land registration, whenever it requires the reporting of sales information, can make a positive contribution to systems of property taxation in which self-assessment is used. Even where properties are assessed periodically by trained assessors, data on the sales prices of transferred properties can be very useful in the assessment process. However, even when the law requires that such information be transmitted to the assessor's office, such as in 
the Philippines, the requisite information frequently is not received by the assessor. This, of course, suggests the need for enforcement practices that ensure the transmission of this data to the appropriate office (Bahl, 1983, p. 236).

With respect to only property taxation, there is little doubt that a simple system of deeds registration, if maintained in an orderly and up-to-date fashion, is considerably more cost-effective than title registration. For tax purposes both systems of land registration offer essentially the same information: the identity of the owner, the area and location of the property, and recent sales prices. Since land registration is seldom initiated strictly for fiscal purposes, most decisions whether to adopt deed or title registration will be strongly influenced by other factors. Nonfiscal considerations may include the desire to use land as credit, improving title security among land-holders, a desire to develop a market in land, the inadequacy of traditional (customary) land-holding arrangements, or a desire to reduce litigation over land (Meeks, 1968, p. 273; West, 1969, pp. 212-214). The significance of these factors and the relative costs of different types of land registration will determine which approach will be adopted in a particular area.

\section{CADASTRAL MAPPING}

Cadastral maps are a critical feature of any good method of land registration, whether of deeds or titles. The essential elements of any cadastral system are an unambiguous definition of all property parcels, accurate cadastral maps, and a property register keyed to each mapped parcel which contains property parcel information (United Nations, 1976, p. 278). At the onset of any attempt at cadastral mapping it is necessary to clearly establish the fiscal and planning uses to which the cadaster will be put, the rights in land to be recorded, and the role of the cadaster in boundary disputes. The answers to these questions will determine the type of cadaster to be executed, the survey methods to be utilized and the procedures to be followed.

Three types of cadasters are distinguished: the fiscal, the legal and the multi-purpose. Each exhibits certain common characteristics, but each varies in the degree of accuracy required and the type and amount of auxiliary data incorporated in the cadaster. Furthermore, each system varies in the contribution which it makes to the effective administration of the property tax.

\section{Fiscal cadasters}

The fiscal cadaster is administratively and technically the simplest cadaster to develop and operate. The primary purpose of this cadaster is to assist in the administration of the property tax. Consequently, the level of accuracy required in determining property boundaries and property areas need not be great. Indeed, because planimetric accuracy is not the primary, or even the secondary, goal of such a system, authorities responsible for its implementation or maintenance can be content to settle for survey techniques which are adequate for fiscal purposes, but which may be seen by some surveyors as totally inadequate (Nittinger, 1975, p. 22). Indeed, if large-scale air photos or maps already exist, the process of parcel identification for a fiscal cadaster can be fairly easy. Large-scale aerial photo- 
graphy, either air photo mosaics or orthophotos, upon which property parcel boundaries can be marked, may be sufficient for the purposes of a fiscal cadaster (Christofi, 1975, p. 27). It has been estimated that using pre-existing orthophotomaps at a scale of 1:10,000 property parcel identification and mapping could be accomplished for a cost of something less than $\$ 1$ per acre (Larsson, 1971, p. 40). Alternatively, if medium-scale $(1: 20,000)$ topographic maps are available it is sometimes possible to use these as is, or to enlarge them, and plot most property parcels with accuracy sufficient for a fiscal cadaster, providing property parcels are not unduly small. As an example, in Barbados it was estimated that nearly 90 per cent of the land parcels could be plotted on base maps using extant maps (United Nations, 1975, p. 473). However, in most contexts in developing countries, adequate aerial photography or large-scale maps suitable for this purpose are not available.

A fiscal cadaster must also identify the individual responsible for paying the property tax, but is not concerned with proof of property ownership or specifying title (United Nations, 1975, p. 473). The difficulties involved in the identification of the individual responsible for payment of the property tax depend upon the legal basis on which the tax is levied. If the tax is levied in rem then the cadastral register need only identify the individual or group of individuals who, by virtue of their use of the land, are eligible to pay the tax. On the other hand, if the tax is levied in personam, the cadaster must identify the actual property owner. This latter case is no easy task, and, as experience with USAID-funded cadastral survey projects in Central America has shown, this can be a major stumbling block in the development of a workable fiscal cadaster (USAID, 1974).

The basis upon which the property tax is levied, capital value or site value, determines the amount of supplemental data the fiscal cadaster requires. If the tax is based on a system of capital or annual (rental) value, the cadastral register must contain an assessment of the capital value of land and property or an estimate of annual income or rental value. A simple site value tax, on the other hand, might base the site value of land on two or three criteria. Site value taxes for agricultural land might be determined using a slope factor and a fertility factor, with the tax due based on the amount of land falling into particular categories. Site value of urban land could be based on the type of neighbourhood in which the property parcel is located (business, residential, industrial) and on the services provided to the property parcel. Such elementary systems of site valuation might be quite appropriate for local governments in developing countries with limited manpower and financial resources to administer a property tax.

If site value taxation is based on more sophisticated means of calculating site value, then a greater range of variables must be included in a fiscal cadaster. Agricultural land valuation variables might include the type of land use or exploitation, soil characteristics, past yields, fixed improvements (clearing, terracing, irrigation), and access to roads or other transportation (Henssen, 1975, p. 58). In urban areas, besides neighbourhood factors and the provision of public services, block location, the amount of street frontage, distance from parks or other public facilities, and other factors, depending on the cultural context, could be used to determine site value. Although such systems of site valuation might be preferred on the grounds that they provide a more equitable and refined tax, the administrative difficulties involved make the more sophisticated methods and requisite cadasters and registers difficult to initiate and maintain. 


\section{Legal cadasters}

Legal cadasters differ from fiscal cadasters not so much in terms of the kind of information they contain, but in the accuracy of the locational, boundary, and ownership data which they include (Nittinger, 1975, p. 22). Because it is a legal document, and frequently represents the last word in court disputes involving title and boundaries, the preparation of a legal cadaster is more expensive than a fiscal cadaster. For the administration of the property tax there is little that the legal cadaster contributes which is not included in a basic fiscal cadaster. Only when the property tax is to be collected in personam does the legal cadaster include data essential to the administration of the tax. A United Nations committee of cadastral mapping experts has suggested that, although the establishment of a legal cadaster is more costly and time-consuming, it is only marginally so, and it is wasteful to establish only a fiscal cadaster (United Nations, 1976, p. 277). While this may be true if there is the need for the cadaster to serve a wide variety of non-fiscal purposes, there is probably little justification if the principal purpose of the cadaster is to aid in the administration of the property tax.

\section{Multi-purpose cadasters}

The multi-purpose cadaster builds upon the data contained in both the fiscal and legal cadaster. Using the individual parcel unit as its base it adds a wide variety of social, economic and environmental data to the cadastral register, or to the registers that are functionally tied to it (Larsson, 1971, p. 63). Dale (1976, pp. 145151) has suggested an incredible list of public and private agencies which might incorporate and utilize the data stored in a multi-purpose cadaster. Because of the diverse uses to which multi-purpose cadasters might be put, their discussion and limited implementation has been in vogue in recent years, particularly in the countries of the developed world where the possibilities of utilizing computer technology have made the concept more attractive. However, because the multipurpose cadaster contributes very little towards the improved administration of the property tax, and because the costs of such a system are clearly beyond the financial capacities of most governments in developing countries, there are few circumstances under which the implementation of one would be advisable for governments in developing countries. Indeed, as Onsrud (1985, p. 305) notes, even in the United States and Canada 'all-inclusive systems are currently out of economic reach of almost all local governments'.

\section{SURVEY METHODS}

The survey method, or combination of methods, chosen to execute a cadastral survey is a function of the type of cadaster desired. Basically, this becomes a question of the necessary degree of accuracy and survey costs. Regardless of the type of cadastral survey, there is a strong tendency among engineers and surveyors to overemphasize the need for exact locational accuracy, even in cases where very general property descriptions would suffice. The tendency also may exist, especially in the case of fiscal cadasters such as the Real Property Tax 
Administration Program in the Philippines, to suggest or insist on the purchase of expensive equipment which does not truly advance the project's objectives (Holland et al., 1980, p. 60). Dale (1976, pp. 280-281) sees this as one of the principal problems existing at the interface between the surveying professional and those who use cadastral maps, and notes that

The cadastral surveyor has a significant contribution to make to society, but this will not be fully realized until he contains his obsession with precise linear and angular measurements.

Three types or classes of cadasters are recognized, with respect to the accuracy of survey information, the graphical, numerical and computational (Blachut, 1979, pp. 239-240). The graphical cadaster provides as its primary product a large-scale map upon which property locations, dimensions and boundaries are plotted. The planimetric accuracy of this cadaster is limited by the map product. Numerical cadasters provide geometric data (lengths and angles) which are tied to a permanent system of geodetic ground control and allow the location of property parcels on the ground through the use of permanent boundary markers. The planimetric accuracy of such surveys is far greater than that of the graphical cadaster. The computational cadaster differs little from the numerical cadaster except that boundary monumentation is reduced to a minimum, and property parcel location and boundaries are computed mathematically using the control net as a datum. It seems reasonable to assert that the accuracy requirements for most fiscal purposes might be adequately satisfied by a graphical cadaster, while the needs of a legal cadaster would require the accuracy which results from a numerical or computational cadaster.

It is critically important to relate survey accuracy and its costs to the value of the land being incorporated into the cadastral survey. In many developing countries, situations commonly arise where the cost of a survey for a piece of land may exceed its value, or in the case of leasehold where the survey costs exceed the expected rental income (Dale, 1976, p. 48). Dale (1976, p. 48) hypothesizes that in developing countries an inverse relationship exists between the costs of a survey and the value of the land. In urban areas where land values are high, costs are low because no extra pay allowances for hardships are required, it is easier to tie into the geodetic control net, and little bush clearance or monumentation are necessary. The opposite is true in rural areas.

Another way of evaluating survey costs and the resulting benefits of a cadaster is to consider the information produced from such a survey as a 'product' (Wunderlich, 1975, pp. 60-61). The utility of such a product lies in its ability to reduce uncertainty and the probability of error. The amount and accuracy of the information required is a function of the marginal cost of each additional piece of information and the financial consequences of errors which could be avoided by the accumulation of additional information. In the case of a fiscal cadaster, errors might include mistaken determinations of areas; inaccurate assessments; incorrect identification of the liable taxpayer; and various errors in names, addresses and indexing. A legal cadaster's possible errors mirror the above and include problems with title security and correct boundary determinations. The potential errors for multi-purpose cadasters are still more numerous. Thus, in determining the level of 
accuracy required, for survey as well as non-survey data, the consequences of error must be considered. If the costs of error are low, a cadaster with tremendous amounts of information of great accuracy is clearly unjustified. On the contrary, if the costs of error are high, then such a survey might be required.

Yet the analysis of these costs and benefits is not easy. It is difficult to apply the principles of modern economic analysis to the question of information generation and use. The long-range time frame (20-30 years) required for the analysis of cadastral information systems, and the intangibility of many of the benefits, represent difficult problems (Larsen,1972, p. 588). Even the economic analysis of cadastral information systems in the United States and Canada proves to be difficult. This is due to scanty information on the economics of these systems, and difficulties inherent in trying to identify and evaluate non-quantifiable benefits (Greulich, 1977, p. 125). These problems are certainly no less intractable in developing countries. It is noted, for example, in the case of the Philippines, 'that the costs of tax mapping have become too high to overcome the inherent short-time horizon that characterizes most political decisions' (Bahl, 1983, p. 235).

The survey method selected for the execution and maintenance of a cadastral survey will depend upon the degree of planimetric accuracy required, the financial resources of the executing agency and the terrain over which the survey is to be conducted. Cadastral survey methods may be grouped into two principal classesthose based on ground survey techniques and those based on aerial photography.

\section{Ground surveys}

Ground-based cadastral surveys, or plane surveys, are executed using a transit, plane table, compass and linen or metal measuring tapes, or with more rigorous ground survey methods employing optical or electronic distance measuring devices and automated data processing (Simpson, 1976, pp. 372-375). Plane table surveying is a technique which can be described as controlled sketching, as it does not demand the level of accuracy required of a geodetic survey. Using visible boundaries and monuments as control, the surveyor uses a transit to record boundary details of property parcels (angles) and measuring tapes or an alidade to determine distances. The method is generally regarded as slow and tedious, and requires relatively large numbers of surveyors and assistants working under careful management if the survey is to be conducted expeditiously. Nevertheless, this labour-intensive method may be preferred (as it has been in India) if wage rates are low and there is a social need to create maximum employment opportunities. In some countries, notably in Latin America, university students are required to perform community service as a prerequisite for graduation, and in some situations they can be enlisted to assist in the field work for a cadastral-mapping programme. For instance, in Cajamarca, Peru, university students used in such a capacity have made a significant contribution to the successful execution of a cadastral mapping programme (Bazan Sifuentes, 1986).

More capital-intensive means of cadastral mapping are also available, but these require greater technical skills of those conducting the survey and, of course, greater investment. These methods require the use of the alidade, a device used in conjunction with a levelling staff to measure distance optically, or the use of even more sophisticated and costly equipment, tachometers, used to measure distance using light waves. 


\section{Aerial surveys}

Cadastral mapping techniques utilizing aerial photography may take several forms. The simplest is to use air photos or uncontrolled air-photo mosaics to identify and demarcate property parcels. The photos or mosaics themselves may be marked by the surveyors and serve as the cadastral record, or cadastral maps may be produced using these as a base (Larsson, 1971, p. 39; Vera, 1964). Because considerable errors in planimetric accuracy can result with these methods, more exact methods are sometimes preferred.

The development and perfection of the production of orthophotos and orthophotomaps during the past decade has proved to be an attractive method for cadastral mapping in developed and developing countries (Beck, 1975; Larsson, 1971, p. 39; Thrower and Jensen, 1976, pp. 52-54; Veign and Reeves, 1973). Orthophotos differ from air-photo mosaics because they are rectified so that images on the orthophoto are in their correct planimetric position. Thus the effects of radial distortion are removed, and land areas can be correctly calculated using a planimeter. As with air-photo mosaics, the cadaster can be plotted directly on the orthophoto creating an orthophotomap, or it can be used as a base for drafting a separate cadastral map.

Photogrammetric techniques represent the most accurate, and probably the most expensive and capital-intensive, means of producing cadastral maps (Harry, 1972; Weissmann, 1975). Based on a network of ground controls and using stereo-pairs of aerial photographs, stereo-plotting instruments (i.e. Kelsh plotter) create successive interlocking stereo models from which topographic and cadastral maps can be derived.

\section{Implementation}

Experience with ground and aerial survey techniques in developing countries has varied. In the Philippines, where numerical cadasters were executed in the early 1960s, surveying experts estimated the costs of cadastral surveying using photogrammetric methods to be approximately 25 per cent less per hectare than traditional ground survey techniques (Marzan et al., 1964, pp. 282-283). At the time, they believed that with additional experience per-unit costs using photogrammetric methods could be reduced to 50 per cent of ground survey costs. On the other hand, experience in Malawi, in the Lilongwe Land Development Project, reaches a contradictory conclusion concerning the relative costs and benefits of ground survey and aerial survey techniques for cadastral mapping (Hodgson, 1977, pp. 155-156). Work there revealed that the cadastral survey costs per unit, using ground survey techniques, were approximately 5 per cent cheaper than the per-acre costs of such mapping using aerial survey methods. Further, a study conducted by project personnel showed the locational accuracy of property parcels plotted from the air photos to be very poor. Fifty per cent of the property parcels mapped using this technique were either not in the right place, not the correct size, or not the correct shape.

Recent experience with cadastral mapping using ground surveys in developing countries indicates that costs per property parcel range between $\$ 2$ and $\$ 5$. Estimates of tax mapping costs in the Philippines have ranged from $\$ 1.40$ to $\$ 2.70$ 
per parcel, and Holland et al. (1980, p. 34) suggest that average costs per parcel probably run about $\$ 2$. In Peru, where USAID has supported tax mapping projects in Huancayo and Cajamarca between 1983 and 1986, costs per parcel have averaged $\$ 5.20$ and $\$ 5.00$ in each city respectively (Fuentes Garcia, 1986, pp. 7-8). In the case of Huancayo these estimates include the cost of two microcomputers, whereas in Cajamarca no computers have been purchased. The comparatively higher costs reported for the Peruvian cities probably reflect the detailed physical inventory required for each property (i.e. construction materials, bathroom fixtures, etc.), while in the Philippines such detail on construction information apparently was not collected.

The most appropriate surveying methodology to be used in any situation will of course depend upon the financial resources available and the requirements of the cadastral survey. Nevertheless, a review of the strengths and weaknesses of ground survey techniques and air photo-based methods by a United Nations committee of experts on cadastral mapping is most instructive (United Nations, 1976, pp. 280281). The principal advantages of ground survey techniques are that the investment required for equipment is small and the process of converting field observations into maps is relatively simple. The negative aspects of such an approach are that a relatively dense network of control points is needed, field procedures are labourintensive and can consume either considerable time or manpower, and if field checks are required at the final mapping stage these can be quite costly. The advantages of utilizing aerial photo-based techniques lie in the fact that comparatively few control points are required, maps or map substitutes can be provided at a wide variety of costs, accuracies and speeds. A large amount of supplemental information potentially useful in assessing land values is provided in the air photos, and the time required to complete any given job will be significantly less than a ground survey. Disadvantages of air photo products are that investment costs for equipment and photos are high, the methods are poorly suited to the subsequent work of cadaster maintenance, and in most cases ground surveys of some kind are necessary to provide the complete information which will be required on the map.

\section{CONCLUSIONS}

Among the basic requirements for the successful administration of the property tax are adequate systems of land registration and cadastral mapping. In either case a range of alternative approaches or methodologies are available. The most suitable alternative in any particular instance will depend on a variety of factors. Critical among these are the legal basis for the property tax and the administrative system which supports it. In a broader sense, both cultural and political practices must also be considered in designing a successful programme of land registration and cadastral mapping. Any one of these factors, or a combination of them, may be overlooked in project planning and implementation. Current experience is replete with cases of project or programme failure because planners and administrators failed to take these factors into account. For example, land titling procedures can cause serious social and political problems in some contexts if officials fail to understand the land tenure practices of the local people. Some projects, while 
technically successful, have been overall failures because they assumed changes in the legal code which never materialized. In other cases legal obstacles have been overcome, but inadequacies in the administrative structure of the government and its civil service have precluded successful implementation.

Sometimes the desire to develop a comprehensive registration and mapping programme can lead to programme failure. This may be caused by a desire to develop projects which include a considerable amount of data beyond those actually required for the practical, and successful, functioning of the system. Undue emphasis may be given to the establishment of a high level of surveying accuracy, or the inclusion of an abundance of property parcel information that is unnecessary for fiscal purposes.

The principal point is that there can be no abstract model of the 'right' land registration and cadastral mapping programme. Each programme must be implemented within the context of a particular cultural, legal, political and administrative situation. Planners and programme officers must be aware not only of the alternative approaches available to them for developing the 'best' possible programme; they must also be aware of, and sensitive to, the legal, administrative, political and cultural context in which the programme will be implemented, and in which it will operate.

\section{ACKNOWLEDGEMENTS}

An earlier version of this paper was initially prepared under the auspices of the Local Revenue Administration Project (United States Agency for International Development, Project No. 936-5303) of the Maxwell School of Public Affairs at Syracuse University. Subsequent support for the preparation of this paper was provided by a Faculty Summer Research Fellowship (1986) from the Graduate School at the University of Akron. The views expressed in this paper are those of the author.

\section{REFERENCES}

Bahl, R. (1983). 'Strengthening the fiscal performance of Philippine local governments'. In: Bahl, R. and Miller, B.D. (eds), Local Government Finance in the Third World: A Case Study of the Philippines, Praeger, New York, pp. 228-255.

Bazan Sifuentes, L. (1986). 'Personal communication', Cajamarca, Peru, June.

Beck, W. (1975). 'Production of cadastral maps for rural and urban areas', World Cartography, 13, 47-56.

Bentsi-Enchill, K. (1964). Ghana Land Law: An Exposition, Analysis, and Critique, Sweet \& Maxwell, London.

Bird, R.M. (1974). Taxing Agricultural Land in Developing Countries, Harvard University Press, Cambridge, MA.

Bird, R.M. (1977). 'Land taxation and economic development: the model of Meijo Japan', Journal of Development Studies, 13(2), 162-174.

Blachut, T.J., Chrzanowski, A. and Saastamoinen, J.H. (1979). Urban Surveying and Mapping, Springer-Verlag, New York.

Christofi, A. (1975). 'Establishment and strengthening of cadastral surveying and mapping services-experiences in Cyprus: a case study', World Cartography, 13, 26-40. 
Codrington, H.W. (1938). Ancient Land Tenure and Revenue in Ceylon, Ceylon Government Press, Colombo.

Dale, P.F. (1976). Cadastral Surveys Within the Commonwealth, Overseas Research Publication No. 23, HMSO, London.

Davis, L.H. (1970). 'Property tax administration in rural local governments of Colombia', Land Economics, 46(2), 146-152.

Elias, T.O. (1971). Nigerian Land Law, 4th edn. Sweet \& Maxwell, London.

Fitch, L.C. (1965). 'Concepts and administration of taxes on property'. In: Joint Tax Program of the OAS and Harvard Law School (eds), Problems of Tax Administration in Latin America, Johns Hopkins University Press, Baltimore, MD, pp. 465-494.

Fuentes Garcia, M. (1986). 'El catastro urbano y el desarrollo local en el Peru'. Paper presented at the Forum-Panel Muncipios y Descentralización, organized by the Instituto de Investigaciones Aplicadas para la Descentralización y Regionalización, March 1986, Huancayo, Peru (18 pp.).

Greulich, G. (1977). 'Cadastre-USA', Surveying and Mapping, 37(3), 221-234.

Harry, H. (1972). 'Photogrammetric cadastral survey and land registry', World Cartography, 12, 101-104.

Henssen, J. L. G. (1975). 'Maintenance of cadastres', World Cartography, 13, 57-61.

Hicks, U. K. (1970). 'Can land be assessed for the purposes of site value taxation?'. In: Holland, D. M. (ed.), The Assessment of Land Value, University of Wisconsin Press, Madison, WI, pp. 9-24.

Hodgson, A. (1977). Surveys for the Lilongwe Land Development Project', Survey Review, 24(186), 147-157.

Holland, D. et al. (1980). An Evaluation of the Real Property Tax Administration Project, Local Revenue Administration Project, Syracuse University, Syracuse, NY, (64 pp.).

Larsen, H. K. (1972). 'On the economics of land and property information systems', Canadian Surveyor, 26(5), 587-590.

Larsson, G. (1971). Land registration in developing countries', World Cartography, 11, 3367.

Maini, K. M. (1967). Land Law in East Africa, Oxford University Press, Nairobi.

Marzan, G. T. et al. (1964). 'Philippine numerical photogrammetric cadastre', Photogrammetric Engineering, 30(2), 278-283.

Meeks, C. K. (1968). Land Law and Custom in the Colonies, 2nd edn. Oxford University Press, London.

Nittinger, J. (1975). 'Cadastral surveying as an instrument of political, economic, and social development', World Cartography, 13, 21-25.

Onsrud, H. J. (1985). 'First steps in modernizing local land records', Surveying and Mapping, 45(4), 305-311.

Regmi, M. C. (1963). Land Tenure and Taxation in Nepal, University of California, Institute of International Studies, Berkeley, CA.

Sazama, G. W. (1970). 'Land taxation: prerequisites and obstacles: Bolivia', National Tax Journal, 23(3), 315-323.

Sazama, G. W. and Davis, L. H. (1973). 'Land taxation and land reform', Economic Development and Cultural Change, 21(4), 642-654.

Simpson, S. R. (1976). Land Law and Registration, Cambridge University Press, Cambridge.

Strasma, J. (1965). 'Market-enforced self-assessment for real estate taxes', Bulletin for International Fiscal Documentation, 19, 353-363, 397-414.

Taylor, M. et al. (1964). Fiscal Survey of Panama: Problems for Reform, Johns Hopkins University Press, Baltimore, MD.

Thrower, N. J. W. and Jensen, J. R. (1976). 'The orthophoto and orthophoto map: characteristics, development, and applications', American Cartographer, 3(1), 39-52.

United Nations-Department of Economic and Social Affairs (1976). 'Report of the meeting of the ad hoc group of experts on cadastral surveying and mapping'. In: Seventh United Nations Regional Cartographic Conference for Asia and the Far East, United Nations, New York, Vol. II, pp. 275-284.

United Nations-Secretariat (1975). 'Site value taxation in developing countries'. In: Bird, 
R. M. and Oldman, O. (eds), Readings on Taxation in Developing Countries, 3rd edn. Johns Hopkins University Press, Baltimore, MD, pp. 470-476.

USAID (United States Agency for International Development) (1974). Intercountry Evaluations of Cadastral Programs: Costa Rica, Guatemala, Nicaragua, and Panama, USAID, Washington, DC.

Veign. J. L. and Reeves, F. B. (1973). 'A case for orthophoto mapping', Photogrammetric Engineering, 34(10), 1059-1063.

Vera, L. (1964). Agricultural Land Inventory Techniques: Experiences of the OAS/Chile Aereo-Photogrammetric Project, Pan-American Union, Washington, DC.

Wang, Y.-C. (1971). 'The fiscal importance of the land tax during the Ch'ing Period', Journal of Asian Studies, 30(4), 829-842.

Weissmann, K. (1975). 'Cadastral surveying by photogrammetry', World Cartography, 13, $41-46$.

West, H. W. (1969). 'The role of land registration in developing countries', Chartered Surveyor, 102(5), 211-221.

Wunderlich, G. (1975). 'Juridical or fiscal cadastre: economics of land information systems'. In: Proceedings of the North American Conference on Modernization of Land Data Systems, North American Institute for the Modernization of Land Data Systems, Washington DC, pp. 47-68. 